\title{
Volatile Compounds Emitted by Diverse Verticillium Species Enhance Plant Growth by Manipulating Auxin Signaling
}

\author{
Ningxiao Li, ${ }^{1}$ Wenzhao Wang, ${ }^{2}$ Vasileios Bitas, ${ }^{3}$ Krishna Subbarao, ${ }^{4}$ Xingzhong Liu, ${ }^{2}$ and \\ Seogchan Kang ${ }^{1,3, \dagger}$ \\ ${ }^{1}$ Intercollege Graduate Degree Program in Plant Biology, The Pennsylvania State University, University Park, PA 16802, U.S.A.; \\ ${ }^{2}$ State Key Laboratory of Mycology, Institute of Microbiology, Chinese Academy of Sciences, Beijing, China; ${ }^{3}$ Department of \\ Plant Pathology \& Environmental Microbiology, The Pennsylvania State University; and ${ }^{4}$ Department of Plant Pathology, \\ University of California, Davis, CA 95616, U.S.A.
}

Accepted 27 March 2018.

\begin{abstract}
Some volatile compounds (VC) play critical roles in intra- and interspecies interactions. To investigate roles of $\mathrm{VC}$ in fungal ecology, we characterized how VC produced by Verticillium spp., a group of broad-host-range soilborne fungal pathogens, affect plant growth and development. VC produced by 19 strains corresponding to 10 species significantly enhanced the growth of Arabidopsis thaliana and Nicotiana benthamiana. Analysis of VC produced by four species revealed the presence of diverse compounds, including those previously shown to affect plant growth. Using $A$. thaliana, we investigated the mechanism underpinning plant growth enhancement by Verticillium dahliae VC. Allometric analysis indicated that $\mathrm{VC}$ caused preferential resource allocation for root growth over shoot growth. Growth responses of A. thaliana mutants defective in auxin or ethylene signaling suggested the involvement of several components of auxin signaling, with TIR3 playing a key role. AUX1, TIR1, and AXR1 were also implicated but appeared to play lesser roles. Inhibition of auxin efflux using 1-naphthylphthalamic acid blocked VC-mediated growth enhancement. Spatial and temporal expression patterns of the auxin-responsive reporter $D R 5:: G U S$ indicated that the activation of auxin signaling occurred before enhanced plant growth became visible. Results from this study suggest critical yet overlooked roles of VC in Verticillium ecology and pathology.
\end{abstract}

All organisms employ multiple mechanisms to recognize, communicate with, and manipulate their neighbors. Secretion

${ }^{\dagger}$ Corresponding author: S. Kang; E-mail: sxk55@psu.edu

Funding: N. Li and V. Bitas have been supported, in part, by a training grant from the United States Department of Agriculture-National Institute for Food and Agriculture (USDA-NIFA) Agriculture and Food Research Initiative Competitive Grants Program (award number 2010-65110-20488). $\mathrm{N}$. Li has been also supported by a fellowship from the Storkan-HanesMcCaslin Foundation. Funds from the USDA-NIFA-SCRI (award number 2010-51181-21069), the Penn State College of Agricultural Sciences (Jeanne \& Charles Rider Endowment Award and Strategic Collaboration Seed Grant), the Huck Institutes of the Life Sciences, and the Penn State Center for Environment geoChemistry and Genomics also supported this work.

*The $\boldsymbol{e}$-Xtra logo stands for "electronic extra" and indicates that 10 supplementary figures are published online.

@ 2018 The American Phytopathological Society of semiochemicals (= infochemicals), diverse types of metabolites that evoke specific behavioral or physiological responses in receiving organisms, is one such mechanism (Law and Regnier 1971). Certain classes of primary and secondary metabolites with high vapor pressure under ambient conditions function as volatile signals. Because volatile compounds (VC) can travel through water, air, and porous soils (Effmert et al. 2012), they can mediate both short- and long-distance organismal interactions even when water as a medium is absent. Plants, animals, and microbes have evolved to produce and recognize semio-VC, and VC-mediated signaling serves diverse vital ecological functions (Baldwin 2010; Bitas et al. 2013; Herrmann 2010; Kaiser 2006; Li et al. 2016; Schenkel et al. 2015). For example, plants attacked by insect herbivores release specific VC to attract parasitoids for pest control (Baldwin 2010). Animals use specific VC to recognize foods, mates, and threats (Bergström 2008). Similarly, accumulating evidence implicates microbial VC in antagonism, mutualism, and regulation of cellular and developmental processes (Bitas et al. 2013; Schmidt et al. 2015).

VC produced by a number of plant-associated fungi have been shown to affect plant physiology, growth, or development. VC released by ectomycorrhizal fungi Laccaria bicolor and truffles induced lateral root growth in both host and nonhost plants (Ditengou et al. 2015; Splivallo et al. 2009). Volatile sesquiterpene (-)-thujopsene, which was shown to be emitted by L. bicolor, was sufficient to stimulate lateral root formation (Ditengou et al. 2015). Similarly, VC produced by multiple Trichoderma spp. enhanced the growth of Arabidopsis thaliana (Hung et al. 2013; Lee et al. 2016). When 6-pentyl-2H-pyran-2-one, an unsaturated lactone produced by several Trichoderma spp., was exogenously applied at concentrations of 50 to $175 \mu \mathrm{M}$, it enhanced plant growth (Garnica-Vergara et al. 2016; Kottb et al. 2015). However plant growth was inhibited when the concentration reached $2 \mathrm{mM}$. The growth of $A$. thaliana was enhanced by VC emitted by 30 phylogenetically diverse bacterial and fungal species (Sánchez-López et al. 2016). Trichoderma VC have been shown to induce systemic resistance in A. thaliana and tomato (Martínez-Medina et al. 2017), illustrating multiple roles of fungal VC in association with plants. Diverse roles of fungal VC in plant interactions were reviewed by $\mathrm{Li}$ et al. (2016).

Here, we investigated how VC produced by all known Verticillium spp. affect plant growth and development, as well as the mechanism underpinning resulting changes. Members of the genus Verticillium cause Verticillium wilt, a destructive 
soilborne disease on numerous crops and other economically or environmentally important plants around the world (Inderbitzin et al. 2011; Pegg and Brady 2002). Among the 10 species described (Inderbitzin et al. 2011), Verticillium dahliae, V. alfalfae, and $V$. longisporum are most destructive, causing billions of dollars of crop loss worldwide (Inderbitzin and Subbarao 2014;

Table 1. Verticillium strains used in this study

\begin{tabular}{|c|c|c|c|}
\hline Strain $^{\mathbf{a}}$ & Species & Host of origin & $\begin{array}{l}\text { Location of } \\
\text { isolation }\end{array}$ \\
\hline PD343 & Verticillium isaacii & Artichoke & $\begin{array}{l}\text { California, United } \\
\text { States }\end{array}$ \\
\hline PD753 & V. isaacii & Spinach seed & $\begin{array}{l}\text { Washington, } \\
\text { United States }\end{array}$ \\
\hline PD401 & V. klebahnii & Lettuce & $\begin{array}{l}\text { California, United } \\
\text { States }\end{array}$ \\
\hline PD659 & V. klebahnii & Lettuce & $\begin{array}{l}\text { California, United } \\
\text { States }\end{array}$ \\
\hline PD690 & V. tricorpus & Tomato & United Kingdom \\
\hline PD703 & V. tricorpus & Carnation & The Netherlands \\
\hline PD736 & V. zaregamsianum & Lettuce & Japan \\
\hline PD739 & V. zaregamsianum & Stock & Japan \\
\hline PD670 & V. albo-atrum & Potato & $\begin{array}{l}\text { Wisconsin, United } \\
\text { States }\end{array}$ \\
\hline PD693 & V. albo-atrum & Potato & United Kingdom \\
\hline PD621 & V. nubilum & Potato & United Kingdom \\
\hline PD702 & V. nubilum & Potato & United Kingdom \\
\hline PD489 & V. alfalfae & Alfalfa & United States \\
\hline PD626 & V. nonalfalfae & Hop & United Kingdom \\
\hline PD810 & V. nonalfalfae & Petunia & Slovenia \\
\hline PD687 & V. longisporium lineage D3 & Horseradish & Germany \\
\hline PD348 & V. longisporium lineage D1 & Cauliflower & $\begin{array}{l}\text { California, United } \\
\text { States }\end{array}$ \\
\hline PD322 & V. dahliae & Lettuce & $\begin{array}{l}\text { California, United } \\
\text { States }\end{array}$ \\
\hline PD413 & V. dahliae & Lettuce & $\begin{array}{l}\text { California, United } \\
\text { States }\end{array}$ \\
\hline
\end{tabular}

a These strains were chosen among those used for a genus-wide phylogenetic analysis of Verticillium (Inderbitzin et al. 2011), with the exception of V. dahliae PD413.
Pegg and Brady 2002). The importance of other newly erected species is only now becoming apparent (Gurung et al. 2015; Kasson et al. 2014; Short et al. 2015). Their soil habitat, longterm persistence in infested soils, and ability to infect a broad spectrum of plants, as well as the scarcity of resistant host germplasm, make effective control of Verticillium wilt very challenging (Agrios 2005; Chawla et al. 2012). Research on Verticillium VC was driven, in part, by our previous study on VC produced by Fusarium oxysporum, another major soilborne fungal pathogen that causes Fusarium wilt. Most $F$. oxysporum strains enhanced the growth of $A$. thaliana and tobacco via VC production; however, VC produced by some strains inhibited or killed A. thaliana (Bitas et al. 2015). Genetic and histochemical analyses revealed the involvement of auxin signaling - in particular, polar auxin transport (PAT) and the functions of AUX1 and TIR1 - in causing growth enhancement and increased lateral root formation by $F$. oxysporum VC (Bitas et al. 2015). The present study was aimed at expanding our knowledge of $\mathrm{VC}$ mediated plant-fungus interactions and their roles in the ecology and pathology of soilborne fungi. A better understanding of this underexplored process will help develop novel disease management strategies.

\section{RESULTS}

Volatile compounds produced by diverse Verticillium spp. enhanced the growth of A. thaliana and Nicotiana benthamiana.

To investigate the effect of Verticillium VC on plant growth and development, seedlings of $A$. thaliana ecotype Col-0 were exposed to VC produced by 19 strains corresponding to 10 Verticillium spp. (Table 1; Supplementary Figure S1). After 14 days of cocultivation, seedlings exposed to Verticillium VC displayed significantly higher shoot fresh weight than those grown in the absence of Verticillium (Fig. 1), with the magnitude of increase ranging from 3.3-fold (V. isaacii PD343) to 5.9fold (V. zaregamsianum PD736). Seedlings exposed to VC also developed more leaves (approximately 9) than control plants

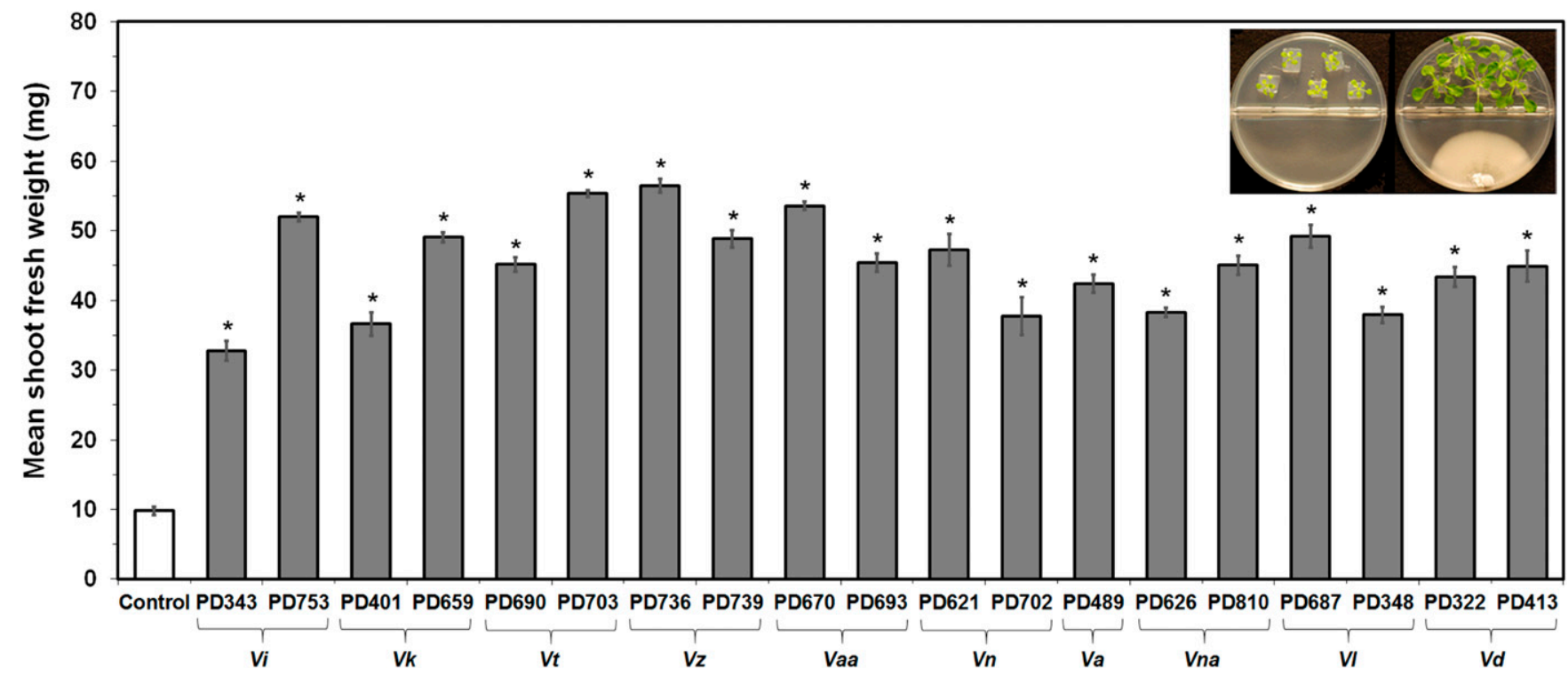

Fig. 1. Growth response of Arabidopsis thaliana to volatile compounds (VC) produced by Verticillium spp. Mean shoot fresh weights of ecotype Col-0 seedlings after 14 days of cocultivation with no fungus (Control) and 19 strains corresponding to 10 Verticillium spp. are shown. Vi $=$ Verticillium isaacii, Vk $=$ V. klebahnii, $V t=V$. tricorpus, $V z=V$. zaregamsianum, Vaa $=V$. albo-atrum, $V n=V$. nubilum, Va $=V$. alfalfae, Vna $=V$. nonalfalfae, Vl $=V$. longisporium, and $V d=V$. dahliae. Values shown correspond to the mean \pm standard error of data from three replicates $(n=15)$. Asterisks indicate significant differences between VC-treated and control seedlings according to Tukey's test at $P=0.05$. The inset shows Col-0 seedlings after cocultivation with no fungus (left) and $V$. dahliae PD413 (right). 
(approximately 7). VC emitted by all Verticillium strains enhanced the growth of Nicotiana benthamiana, ranging from 2.3-fold (V. alfalfae PD489) to 3.2-fold ( $V$. dahliae PD322) (Supplementary Fig. S2). However, the number of leaves did not increase.

Growth responses of eight Arabidopsis ecotypes to VC produced by two $V$. dahliae strains, PD322 and PD413, were also measured (Supplementary Fig. S3). All of the ecotypes exhibited significantly increased shoot biomass compared with controls. With the exception of $\mathrm{C} 24$, which only displayed increased lateral root elongation, all ecotypes exposed to $\mathrm{VC}$ displayed significantly higher lateral root number and density than control plants.

Growth enhancement by $V$. dahliae $\mathrm{VC}$ became visible as early as 5 to 7 days after cocultivation, and the degree of growth enhancement correlated with the duration of VC exposure.

To determine how the growth of A. thaliana changed during cocultivation with $V$. dahliae strains PD312 and PD413, seedlings were collected at multiple time points for shoot weight measurement starting at day 3 (Fig. 2). Measurement of root fresh weight started at day 7 , because accurate weight measurement at earlier time points was difficult. Differences in shoot growth between $\mathrm{VC}$-exposed and control plants became notable between days 5 and 7 (Fig. 2A). Similarly, enhanced root growth (Fig. 2B) and lateral root development (Supplementary Fig. S4)
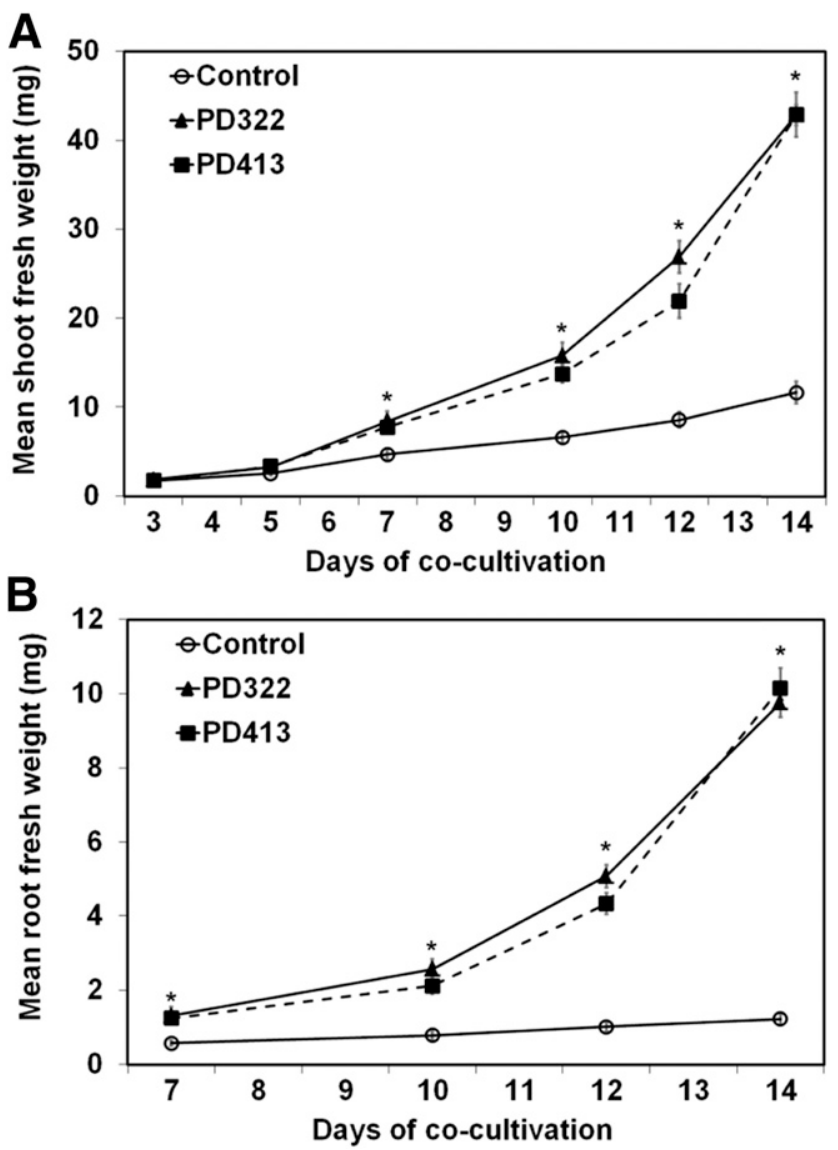

Fig. 2. Growth of Arabidopsis thaliana during 14 days of cocultivation with two Verticillium dahliae strains. A, Shoot and B, root fresh weights of Col-0 at multiple time points during cocultivation with no fungus (Control) and $V$. dahliae strains PD322 and PD413 are shown. Values shown correspond to the mean \pm standard error of data from three replicates $(n=15)$. Asterisks indicate significant differences between volatile compound-treated and control samples according to Tukey's test at $P=0.05$. were apparent at day 7. As expected from the growth curves (Fig. 2), VC-exposed plants exhibited constantly higher relative growth rate of shoots and roots compared with those of control plants (Table 2). Between days 10 and 14, a sharp increase in biomass occurred, resulting in threefold (shoot) and ninefold (root) increases at day 14 (Fig. 2).

To further investigate the relationship between the degree of growth enhancement and the duration of VC exposure, $V$. dahliae culture was removed at 5, 7, and 10 days after cocultivation; however, A. thaliana seedlings were not harvested until day 14 (Supplementary Fig. S5). Five days of VC exposure were insufficient to enhance growth. However, when VC exposure was extended to 7 days, 90\% (PD322) and 70\% (PD413) increases in shoot fresh weight were observed. After 10 and 14 days of VC exposure, two- and fourfold increases were observed, respectively.

Other changes in A. thaliana caused by $V$. dahliae VC.

In addition to significantly increased lateral root number and density in response to $V$. dahliae $\mathrm{VC}$, leaf surface area, total root length, and root branching also increased (Fig. 3). However, the primary root length (Fig. 3B) and leaf chlorophyll content (Fig. 3D) did not change significantly compared with controls. Comparison of leaf relative water content (Fig. 3E) showed that increased shoot fresh weight was not due to increased water accumulation.

To investigate the coordination of growth between shoots and roots in response to Verticillium VC, we calculated the allometric coefficient, $k$, an approach that has been widely used to study resource allocation (Crookshanks et al. 1998; Hunt 2017; Jin et al. 2009; Ristova and Busch 2014; Shipley and Meziane 2002; Veresoglou et al. 2012; Wright and Westoby 2000). A value of $k>1$ indicates that roots grow faster than shoots, suggesting more resource allocation to root growth. Compared with the $k$ of control plants, plants exposed to $V$. dahliae VC displayed significantly higher $k$ values (Fig. 4).

\section{Several components of auxin signaling are involved} in $\boldsymbol{V}$. dahliae VC-mediated growth enhancement.

Both auxin and ethylene affect many aspects of plant growth and development, including primary root elongation, lateral root development, and apical hook formation (Muday et al. 2015; Růzicka et al. 2007). The formation of highly branched roots (Fig. 3F) and preferential enhancement of root growth (Fig. 4) in response to $V$. dahliae $\mathrm{VC}$ suggested the involvement of these hormones in regulating plant responses. To test this hypothesis, we screened $A$. thaliana mutants impaired in PAT, auxin signaling, or ethylene signaling. The mutants included pin-formed 1 (pin1-7), auxin-resistant 1 (aux1-7), transport inhibitor response 3 (tir3-101), transport inhibitor response 1 (tirl-1), auxin-resistant 1 (axrl-3), ethylene response 1 (etrl-1), and ethylene-insensitive 2 (ein2). The tir3-101 mutation caused aberrant morphologies, including vitreous leaves, no lateral root formation, and restricted leaf expansion and petiole

Table 2. Influence of Verticillium dahliae volatile compounds on the relative growth rate of shoots (RGRS) and the relative growth rate of roots (RGRR) of Arabidopsis thaliana ecotype Col-0 at different stages of cocultivation

\begin{tabular}{|c|c|c|c|c|c|c|c|c|}
\hline \multirow[b]{2}{*}{ Treatments } & \multicolumn{5}{|c|}{$\begin{array}{c}\text { RGRS } \\
\left(\mu g^{-1} \text { day }^{-1}\right) \\
\text { per day range }\end{array}$} & \multicolumn{3}{|c|}{$\begin{array}{c}\text { RGRR } \\
\left(\mu g^{-1} \text { day }^{-1}\right) \\
\text { per day range }\end{array}$} \\
\hline & 3-5 & 5-7 & $7-10$ & 10-12 & 12-14 & $7-10$ & 10-12 & 12-14 \\
\hline Control & 0.296 & 0.172 & 0.127 & 0.124 & 0.131 & 0.098 & 0.137 & 0.096 \\
\hline PD322 & 0.327 & 0.432 & 0.221 & 0.272 & 0.230 & 0.256 & 0.347 & 0.306 \\
\hline PD413 & 0.374 & 0.346 & 0.189 & 0.222 & 0.352 & 0.181 & 0.329 & 0.453 \\
\hline
\end{tabular}


elongation, which is consistent with the critical role of TIR3 in growth and development (Gil et al. 2001; Guo et al. 2013). Growth of this mutant was not enhanced by V. dahliae VC (Fig. 5). Three other mutants, including aux 1-7, tirl-1, and axr 1-3, positively responded to $V$. dahliae $\mathrm{VC}$ but the degree of growth enhancement was lower than that in Col-0 (Fig. 5). In contrast, the responses of pin 1-7, etr1-1, and ein 2 were indistinguishable from that of Col-0 (Fig. 5). Our previous study also showed the involvement of auxin signaling in mediating growth enhancement by F. oxysporum VC but did not include axrl-3 and tir3101 (Bitas et al. 2015). Growth responses of these mutants to VC from two $F$. oxysporum strains used in our previous study, NRRL 26379 and NRRL 38335, were evaluated. The tir3 mutant failed to respond to $F$. oxysporum $\mathrm{VC}$, and the growth of axrl-3 was enhanced by $F$. oxysporum VC but the degree of enhancement was lower than that in Col-0 (Supplementary Fig. S6).

To analyze spatial and temporal patterns of auxin response to $V$. dahliae VC, we employed a transgenic Col-0 carrying the auxin-responsive reporter DR5::GUS (Jefferson et al. 1987; Ulmasov et al. 1997. After 7 days of cocultivation with $V$. dahliae, higher $\beta$-glucuronidase (GUS) activity was observed in root tips compared with control plants (Fig. 6; Supplementary Fig. S7). GUS expression was highly induced in the primary root cap and meristem and was also observed in stele and epidermal cells (Fig. 6B). Lateral root primordia of VC-treated plants, but none in control plants, displayed GUS activity (Fig. 6A). After 14 days of cocultivation, differences between treatments were less pronounced (Supplementary Fig. S8). Most of the root tips of VC-exposed plants (85\% for PD322 and $96 \%$ for PD413) only displayed very weak staining, while $98 \%$ of the root tips of control plants fell into this category.

\section{PAT is important for growth enhancement} by $V$. dahliae VC.

To determine whether PAT is critical for $V$. dahliae $\mathrm{VC}$ mediated growth enhancement, we evaluated plant growth in the presence of different concentrations of 1-naphthylphthalamic acid (NPA), an auxin efflux inhibitor that has been shown to disrupt lateral root development and leaf expansion by blocking the establishment of optimal auxin concentrations required for normal leaf growth and lateral root initiation (Casimiro et al. 2001; Ljung et al. 2001; Reed et al. 1998). After growing A. thaliana on Murashige and Skoog (MS) medium supplemented with varying concentrations of NPA in the presence and absence of $V$. dahliae, both lateral root density and total leaf surface area were assessed (Fig. 7). In the presence of $1 \mu \mathrm{M}$ NPA, enhanced lateral root formation by $V$. dahliae VC was still observed at days 7 and 14 (Fig. 7A) but the degree of

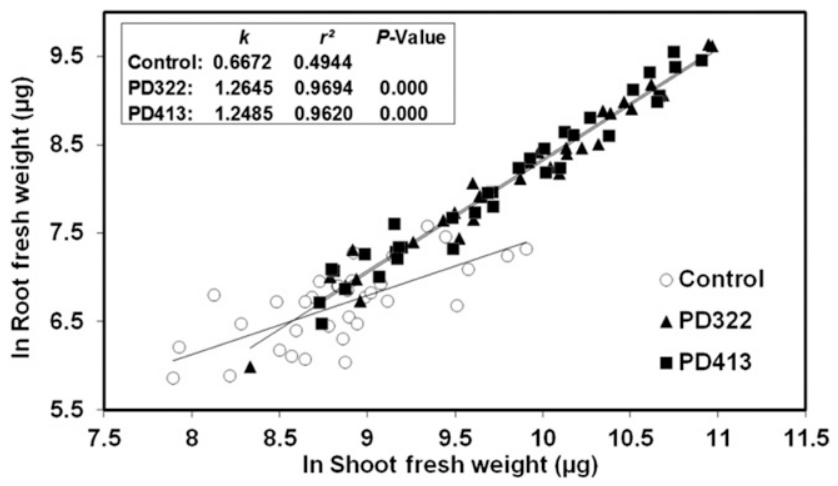

Fig. 4. Allometric analysis of Arabidopsis thaliana growth pattern after exposure to volatile compounds produced by Verticillium dahliae. Shoot and root fresh weights of Col-0 seedlings were measured after 7, 10, 12, and 14 days of cocultivation with no fungus (Control) and $V$. dahliae strains PD322 and PD413. The relationship between $\ln$ shoot fresh weight and $\ln$ root fresh weight of Col-0 is shown. Each value corresponds to the mean of data from three replicates $(n=15)$. Inset shows the allometric coefficient $(k)$ as the slope of the linear regression model through the transformed weight means; $r^{2}$ indicates the fitness of the linear regression model to a set of observations. Statistical analysis was performed to demonstrate significant differences in $k$ value among the treatments.
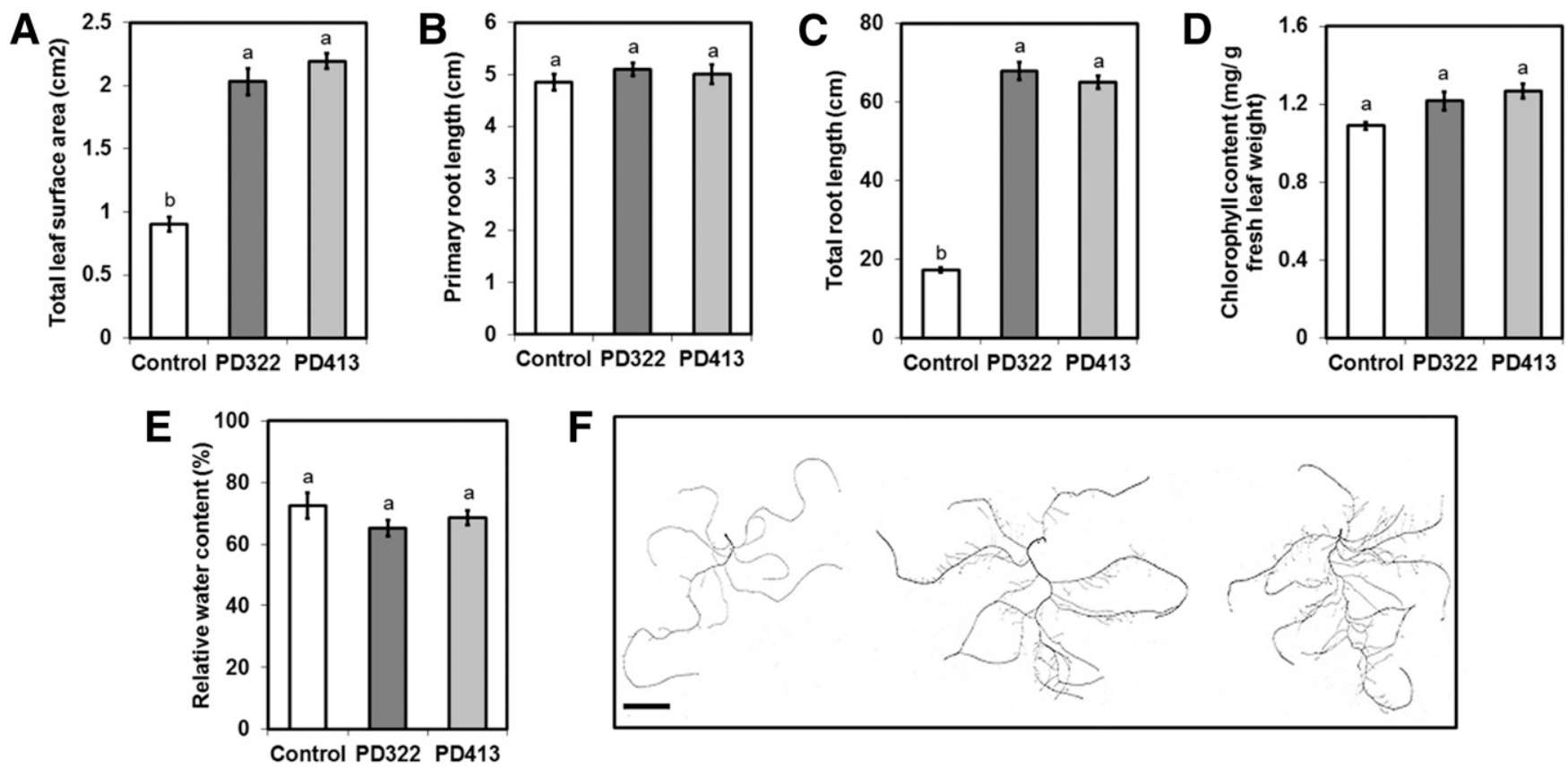

Fig. 3. Assessment of multiple changes in Arabidopsis thaliana upon exposure to Verticillium dahliae volatile compounds (VC). A, Total leaf surface area; $\mathbf{B}$, primary root length; $\mathbf{C}$, total root length; D, leaf chlorophyll content; and $\mathbf{E}$, leaf relative water content of Col-0 seedlings after 14 days of cocultivation with no fungus (Control) and $V$. dahliae strains PD322 and PD413 are shown. Values shown correspond to the mean \pm standard error of data from three replicates $(n=15)$. Different letters indicate significant differences among treatments according to Tukey's test at $P=0.05$. F, Root architectures of representative plants (from left to right: control, PD322, and PD413) are shown. Scale bar $=1 \mathrm{~cm}$. 
enhancement was lower than that of those grown in the absence of NPA. The degree of enhancement was further reduced as the concentration of NPA increased. In the presence of $10 \mu \mathrm{M}$ NPA, lateral root formation in VC-exposed plants was indistinguishable from that in control plants. To confirm that NPA disrupted PAT, we analyzed GUS activity in the DR5::GUS reporter line cultured on NPA-amended medium after 7 days of cocultivation with $V$. dahliae. In the presence of $10 \mu \mathrm{M}$ NPA, $V$. dahliae $\mathrm{VC}$ failed to increase auxin in primary roots, and patterns in VC-exposed plants were comparable with those in control plants (Supplementary Fig. S9). Although the total leaf surface area was also negatively affected by NPA, it still was significantly larger in VC-exposed plants than in control plants, even in the presence of $10 \mu \mathrm{M}$ NPA (Fig. 7B), suggesting that additional mechanisms may be involved in regulating leaf expansion in response to $\mathrm{VC}$. We did not notice any differential GUS expression in leaves among all of the treatments.

\section{Analysis of VC produced by Verticillium spp.}

As an initial step toward the identification of Verticillium VC that affect plant growth and development, we analyzed VC produced by five strains corresponding to four species via gas chromatography-mass spectrometry (GC-MS) (Table 3; Supplementary Fig. S10). The compounds produced by all five strains were 2-methyl-1-propanol and phenylethyl alcohol. Earlier studies reported that these two compounds did not affect plant growth (Hung et al. 2014; Naznin et al. 2013). Some compounds, including 2-methyl-1-butanol, 3-octanone, 3-octanol, 1-octen-3-ol, and himachala-2,4-diene, were produced by at least three strains. Some strain-specific compounds were detected. For instance, V. longisporium PD687 produced 2, 3-butanediol, acetoin, 1-hexanol, and 3-ethyl-4-methyl-3-penten2-one. V. albo-atrum PD670 emitted two unique sesquiterpenes, including $\beta$-caryophyllene and $\alpha$-amorphene. Interestingly, V. isaacii PD753 produced methyl salicylate, a signaling molecule that controls long-distance, systemic plant defense responses.

\section{Fungal $\mathrm{CO}_{2}$ contributes to enhancing plant growth but is not the only factor.}

$\mathrm{CO}_{2}$ produced via microbial respiration has been shown to contribute to enhanced plant growth (Ditengou et al. 2015; Kai and Piechulla 2009; Meldau et al. 2013; Naznin et al. 2013; Piechulla 2017). $\mathrm{KOH}$ or $\mathrm{Ba}(\mathrm{OH})_{2}$ has been employed to trap $\mathrm{CO}_{2}$ (Bitas et al. 2015; Kai and Piechulla 2009; Lee et al. 2016; Meldau et al. 2013). In the presence of $0.1 \mathrm{M} \mathrm{KOH}$, the growth of control plants was severely impaired (Fig. 8A), suggesting that photosynthesis is required for growth in the presence of $0.25 \%$ sucrose. The growth of $V$. dahliae $\mathrm{VC}$-exposed plants was also reduced under the same condition (Fig. 8B) but, when compared with control plants, their growth was still significantly increased (Fig. 8). We supplemented 3\% sucrose to plant culture medium to eliminate the need for photosynthesis. In the presence of $3 \%$ sucrose, the growth of control plants was similar between the no-KOH and $\mathrm{KOH}$ treatments (Fig. 8B), and the degree of $\mathrm{VC}$-mediated growth enhancement remained unaffected (PD322) or slightly but not significantly reduced (PD413) compared with that observed in the absence of $\mathrm{KOH}$ (Fig. 8B). Some Verticillium strains that caused significantly different degrees of growth enhancement (Fig. 1) were indistinguishable in colony size (indirectly suggesting similar metabolic activities and amounts of $\mathrm{CO}_{2}$ produced). Examples include $V$. isaacii PD343 and PD753 and V. longisporium PD687 and PD348 (Fig. 1). As for V. tricorpus, although the colony size of PD690 was larger than PD703, the degree of growth enhancement by PD690 VC was lower. These results suggested the involvement of compounds other than $\mathrm{CO}_{2}$ in growth enhancement.

\section{DISCUSSION}

Both beneficial and pathogenic microbes produce VC that affect plant fitness, growth, or development (Bailly and Weisskopf 2012; Bitas et al. 2013; Chung et al. 2016; Cordovez et al. 2017; Hung et al. 2015; Li et al. 2016), suggesting that this mechanism may play critical roles in microbial ecology and interaction with plants. Similar to VC produced by root pathogen $F$. oxysporum (Bitas et al. 2015), VC produced by all described Verticillium spp. also significantly affected the growth and development of $A$. thaliana and tobacco (Figs. 1, 2, and 3). Growth responses of $A$. thaliana to hormone signaling mutants and to inhibition of auxin transport, as well as spatial and temporal patterns of auxin response, indicate that VC produced by both fungi work through auxin signaling. Further delineation of the molecular mechanism underlying VCmediated growth manipulation may guide the development of novel strategies for boosting plant growth while helping control pathogens. However, as discussed below, there exist a number of complex questions that need to be investigated so as to realize this potential.

\section{Potential roles of $\mathrm{VC}$ produced by soilborne fungi in rhizosphere competence and root infection.}

Although many studies (Bailly and Weisskopf 2012; Kanchiswamy et al. 2015a; Li et al. 2016; Morath et al. 2012; Sánchez-López et al. 2016) have shown that microbial VC enhance the growth of both shoots and roots, this study is the first to reveal that fungal VC shift resource allocation from shoots to roots (Fig. 4). Such manipulation results in accelerated root growth and development, likely benefiting Verticillium spp. The rhizosphere attracts diverse microbes due to the availability of
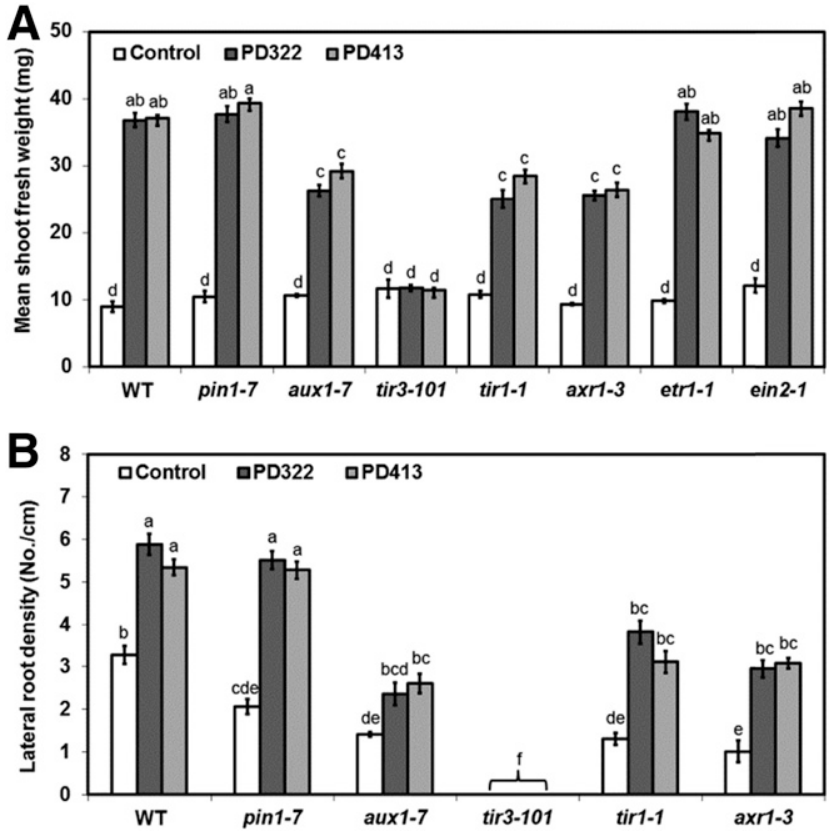

Fig. 5. Growth and developmental responses of Arabidopsis thaliana hormonal signaling mutants to Verticillium dahliae volatile compounds. A, Shoot fresh weights of Col-0 (WT) and its mutants defective in auxin signaling (pin1-7, aux1-7, tir3-101, tirl-1, and axr1-3) or ethylene signaling (etr1-1 and ein2) after 14 days of cocultivation with no fungus (Control) and $V$. dahliae strains PD322 and PD413 are shown. B, Lateral root densities of Col-0 and auxin signaling mutants are shown. Values shown correspond to the mean \pm standard error of data from three replicates $(n=15)$. Different letters indicate significant differences among the treatments according to Tukey's test at $P=0.05$. 
rich nutrients such as root exudates, dead root cells, and soil nutrients mineralized by plants and rhizosphere microbes (de Weert and Bloemberg 2007). Increased nutrient availability, resulting from $\mathrm{VC}$-induced increase in root biomass and lateral root formation, would certainly support the growth of Verticillium spp. Additional benefit may come from root developmental changes. Verticillium spp. enter the vascular system of roots through physical wounds created at the sites of lateral root formation (Fradin and Thomma 2006; Klosterman et al. 2009). Increased formation of lateral roots upon exposure to Verticillium VC (Figs. 3 and 6) could facilitate infection by creating more potential entry points to the vascular system. Similar changes in root development were also observed upon exposure to F. oxysporum VC (Bitas et al. 2015). Evaluation of other root-associated fungi will reveal whether VC-mediated manipulation of root growth and development represents a conserved mechanism underlying rhizosphere competence and root colonization.

\section{Which VC manipulate plant growth and development?}

This is one of the most critical questions that should be pursued to understand the roles and underlying mechanisms of VC-mediated manipulation of plants. Some microbial VC have been shown to affect plant growth through application of their synthetic versions (Hung et al. 2015; Kanchiswamy et al. 2015b; Li et al. 2016). However, their roles in natural habitats remain to be validated. Because microbes release many $\mathrm{VC}$ simultaneously, with their composition and amounts being highly dynamic (Bitas et al. 2013; Hutchinson 1973; Kanchiswamy et al. 2015b; Korpi et al. 2009; Morath et al. 2012), application of synthetic versions may be inadequate for identifying which VC regulate plant responses in natural habitats. Characterization of the fitness and behavior of microbial mutants defective in the synthesis of candidate VC would be needed.

The four Verticillium spp. analyzed produced diverse VC (Table 3), including some that have been shown to affect plants such as 3-octanone, 1-octen-3-ol, 2, 3-butanediol, acetoin, 1hexanol, and $\beta$-caryophyllene. 3-Octanone and 1-octen-3-ol, two commonly produced fungal VC, inhibited $A$. thaliana growth and also induced an oxidative burst, leading to bleaching (Hung et al. 2014; Splivallo et al. 2007). Both 2,3-butanediol and acetoin are well-known plant-growth-enhancing compounds produced by many bacteria (Blom et al. 2011; Ryu et al. 2003), and the latter was recently found to be produced by $V$. longisporium (Rybakova et al. 2017). Sesquiterpene $\beta$-caryophyllene enhanced the growth of lettuce and turnip plants (Minerdi et al. 2011; Yamagiwa et al. 2011) but did not affect $A$. thaliana (Ditengou et al. 2015).

In addition to manipulating plants, Verticillium $\mathrm{VC}$ may also affect other microbes. For example, 1-octen-3-ol has been shown to control fungal spore production and germination (Chitarra et al. 2004; Nemčovič et al. 2008). V. longisporium increased the production of antimicrobial VC, including 1-butanol, upon exposure to biocontrol agent Paenibacillus polymyxa
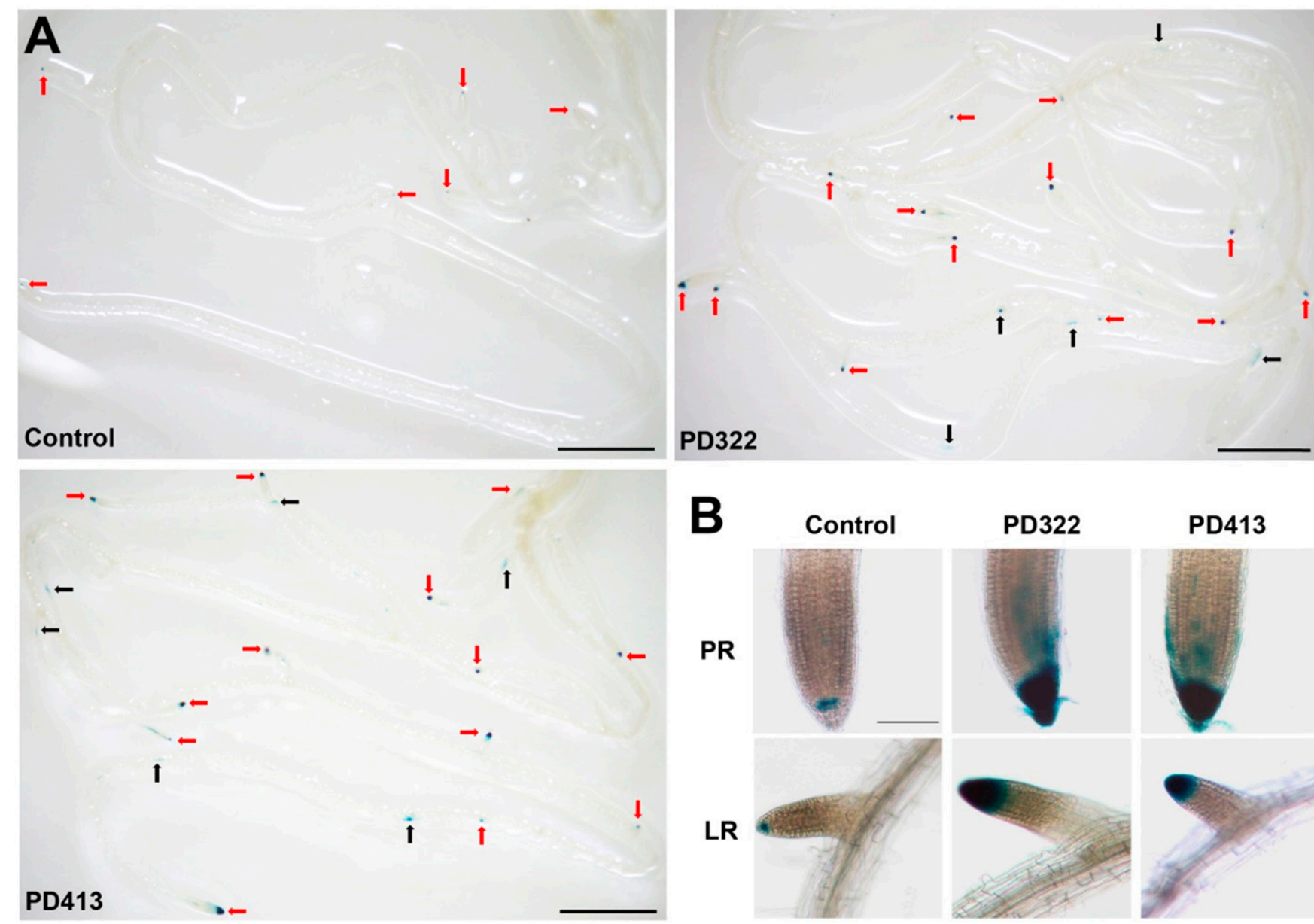

Fig. 6. $\beta$-Glucuronidase (GUS) activity in roots of transgenic Arabidopsis thaliana Col-0 containing DR5::GUS. Plants were stained for GUS activity after 7 days of cocultivation with no fungus (Control) and Verticillium dahliae strains PD322 and PD413. A, Root tips and lateral root primordia expressing GUS are marked with light and dark arrows, respectively. Scale bar $=500 \mu \mathrm{m}$. B, Enlarged primary root (PR) and lateral root (LR) tips of control plants and those exposed to $V$. dahliae volatile compounds are shown. Scale bar $=100 \mu \mathrm{m}$. 
(Rybakova et al. 2017). This alcohol was also produced by V. longisporium PD687 (Table 3). Some sesquiterpenes, including $\beta$-caryophyllene, $\alpha$-amorphene, 4,11 -selinadiene, and himachala-2,4-diene (Table 3), may function as chemical weapons to suppress the growth of competing microbes. These compounds displayed antimicrobial and insect-repellent activities (Kramer and Abraham 2012).

How do plants process semio-fungal VC?

Our results (Figs. 6 and 7), as well as previous studies, (Bailly et al. 2014; Bitas et al. 2015; Garnica-Vergara et al. 2016; Zhang et al. 2007), indicated the involvement of auxin signaling in mediating growth enhancement and modulation of root growth by microbial VC. The TIR 3 gene, which encodes a protein related to the Drosophila protein Calossin/Pushover (Xu et al. 1998), is critical for A. thaliana response to VC emitted by both $F$. oxysporum and $V$. dahliae (Fig. 5). Although the precise mode of action and function of TIR3 remains to be unveiled, TIR3 has been shown to affect basipetal auxin transport and auxin signaling (Guo et al. 2013; Ruegger et al. 1997). TIR3 affects the level of PIN1 in leaf pavement cells and root cells and also regulates PIN1 protein distribution (Gil et al.
2001; Guo et al. 2013). However, considering that the pin1 mutant responded to $V$. dahliae VC just like Col-0 (Fig. 5), the lack of response to $V$. dahliae $\mathrm{VC}$ in the tir3 mutant probably is not due to the disruption of PIN1 functionality by this mutation. AUX1, TIR1, and AXR1 appeared to play minor roles in modulating plant response to $V$. dahliae VC. However, in our previous study (Bitas et al. 2015), the VC from $F$. oxysporum failed to enhance the growth of the auxl and tirl mutants, suggesting that the two pathogens manipulate auxin signaling through both common and pathogen-specific components.

Auxin accumulation had been induced before growth response became evident but subsequently went down (Fig. 6). Similarly, VC from both Bacillus subtilis and F. oxysporum induced $D R 5:: G U S$ expression after 7 to 8 days of cocultivation; however, its expression subsequently went down to the level indistinguishable from that in control plants (Bitas et al. 2015; Zhang et al. 2007). The data showing that the magnitude of growth enhancement correlates with the duration of VC exposure suggest that auxin accumulation during the early stage of cocultivation may not be sufficient. In agreement with several previous studies (Bailly et al. 2014; Bitas et al. 2015; Garnica-Vergara et al. 2016; Zhang et al. 2007), PAT is also
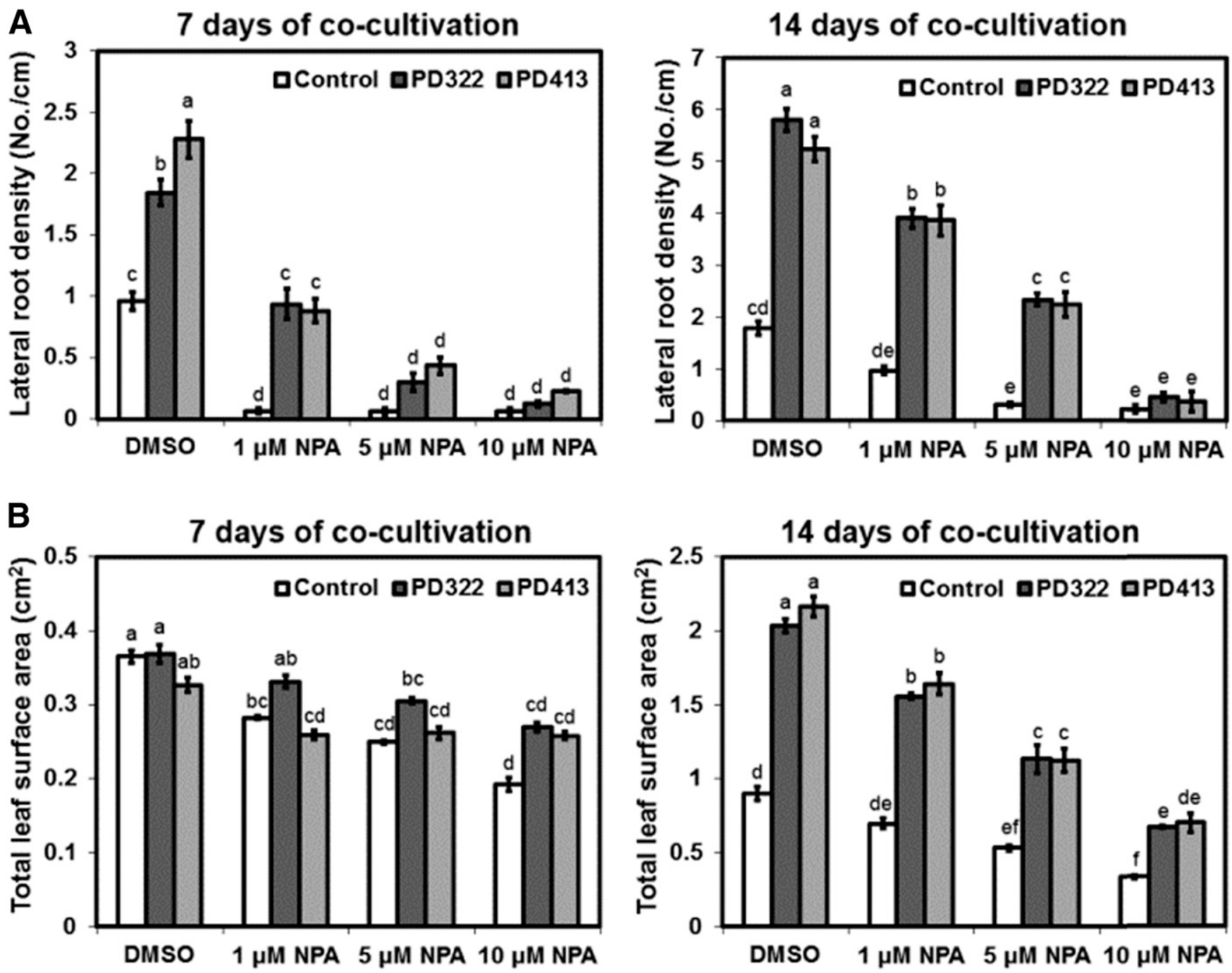

Fig. 7. Inhibition of polar auxin transport interrupted Verticillium dahliae volatile compound-mediated growth enhancement in Arabidopsis thaliana. A, Lateral root density and $\mathbf{B}$, total leaf surface area of Col-0 seedlings cocultivated with no fungus (Control) and V. dahliae strains PD322 and PD413 for 7 and 14 days in the presence of 1,5, and $10 \mu \mathrm{M}$ 1-naphthylphthalamic acid (NPA) are shown. The same volume of dimethyl sulfoxide (DMSO) was used for all treatments, including the control. Values shown correspond to the mean \pm standard error of data from three replicates $(n=15)$. Different letters indicate significant differences among the treatments according to Tukey's test at $P=0.05$. 
required for $V$. dahliae $\mathrm{VC}$-mediated change in root development (Fig. 7). However, even in the presence of $10 \mu \mathrm{M}$ NPA, the leaf surface area of plants exposed to $V$. dahliae VC still increased compared with that of control plants, raising the possibility that $V$. dahliae VC-mediated leaf expansion involves other signals. Production of volatile hormone methyl salicylate by $V$. isaacii PD753 (Table 3) raised the possibility that fungal VC may affect additional hormonal signaling pathways. However, because only one of five strains analyzed produced this compound, its role in modulating growth is unclear. Although growth responses of etrl and ein 2 to V. dahliae and etrl to $F$. oxysporum VC were comparable with that of Col-0 (Fig. $5)$, whether ethylene signaling is involved in this process requires inclusion of more mutants.

\section{MATERIALS AND METHODS}

Fungal cultures and plant materials.

Verticillium strains used in this study are shown in Table 1. F. oxysporum strains NRRL 26379 and NRRL 38335 were obtained from the USDA ARS Culture Collection (Peoria, IL). All strains were maintained as conidia suspension in $20 \%$ glycerol at $-80^{\circ} \mathrm{C}$ and were revitalized by inoculating on halfstrength potato dextrose agar (PDA; Becton, Spark, MD) at room temperature. Seed of A. thaliana ecotypes were purchased from Lehle Seed Co. (Round Rock, TX). The mutants of Col-0 used in this study, including CS237 (etr1-1), CS3074 (aux1-7), CS3075 (axr1-3), CS3798 (tir1-1), CS3928 (tir3-101), CS8844 (ein2), and SALK_047613 (pin1-7), were obtained from the Arabidopsis Biological Resource Center at the Ohio State University. Because homozygous pinl-7 mutant is infertile, only seedlings that formed an elongated primary root (= homozygous mutants) were used for evaluating their response to fungal VC. Transgenic Col-0 containing DR5::GUS (Jefferson et al. 1987) was provided by D. Desveaux at the University of Toronto. M. Axtell at Penn State provided N. benthamiana seed.
I-plate assay to assess the effect of Verticillium VC on plant growth.

A bipartite Petri plate (I-plate; Fig. 1), which only allows VC-mediated interaction between Verticillium spp. and plants, was used as described in earlier studies (Bitas et al. 2015; Naznin et al. 2013; Paul and Park 2013). Seed treatment was conducted as described by Bitas et al. (2015). Seed of Nd-0 and Kin-0 were stratified for 1 week to increase germination rate. MS medium (Sigma-Aldrich, St. Louis) supplemented with $0.8 \%(\mathrm{wt} / \mathrm{vol})$ agar and $0.25 \%(\mathrm{wt} / \mathrm{vol})$ sucrose, with the exception of the experiment shown in Figure 8, was used for growing plants. One plug of fungal culture on PDA ( $5 \mathrm{~mm}$ in diameter) and 5-day-old plant seedlings were transferred to each I-plate on the same day. Growth chamber conditions for cocultivation were $22^{\circ} \mathrm{C}, 12 \mathrm{~h}$ of light $\left(4,500 \mathrm{lux}, 60 \mu \mathrm{mol}\right.$ photons $\left.\mathrm{m}^{-2} \mathrm{~s}^{-1}\right)$, and $60 \%$ relative humidity.

Analysis of growth, root development, and physiological changes caused by Verticillium VC.

Shoot and root fresh weight, leaf surface area, primary and total root length, lateral root density, chlorophyll content, and relative water content ([fresh weight - dry weight]/[turgid weight - dry weight]) were measured as previously described (Bitas et al. 2015). Primary root length was measured via analysis of photographed roots using ImageJ. Seedlings were collected at $3,5,7,10,12$, and 14 days of cocultivation with $V$. dahliae strains PD312 and PD413 to measure shoot fresh weight. Root fresh weight was measured only for the samples collected at days $7,10,12$, and 14 . The method described by Hiscox and Israelstam (1979) was employed to measure chlorophyll content. Relative growth rate was calculated using the formula $\left(\ln \mathrm{W}_{2}-\ln \mathrm{W}_{1}\right) / \mathrm{dt}_{(2-1)}$. Shoot and root fresh weights at days 7,10 , and 14 were used to calculate the allometric growth coefficient, $k$, using the equation $\log \mathrm{R}_{\mathrm{w}}=\log b+k \log \mathrm{S}_{\mathrm{w}}$, where $b$ is a constant and $\mathrm{R}_{\mathrm{w}}$ and $\mathrm{S}_{\mathrm{w}}$ correspond to root and shoot fresh weights, respectively (Hunt 2017).

Table 3. Volatile compounds produced by five Verticillium strains

\begin{tabular}{|c|c|c|c|c|c|c|c|c|c|}
\hline \multirow[b]{2}{*}{$\mathbf{N}^{\mathbf{b}}$} & \multirow[b]{2}{*}{ Compound $^{c}$} & \multirow[b]{2}{*}{ Formula } & \multirow[b]{2}{*}{ RIcal $^{\mathbf{d}}$} & \multirow[b]{2}{*}{ RIref $^{\mathbf{e}}$} & \multicolumn{5}{|c|}{ Verticillium strains analyzed ${ }^{a}$} \\
\hline & & & & & $\operatorname{PD322}(V d)$ & $\operatorname{PD413}(V d)$ & PD687 $(V l)$ & PD670 (Vaa) & PD753 (Vi) \\
\hline 1 & 2-Methyl-1-propanol & $\mathrm{C}_{4} \mathrm{H}_{10} \mathrm{O}$ & 1068 & 1068 & $\sqrt{ }$ & $\sqrt{ }$ & $\sqrt{ }$ & $\sqrt{ }$ & $\sqrt{ }$ \\
\hline 2 & 3-Methyl-1-butanol & $\mathrm{C}_{5} \mathrm{H}_{12} \mathrm{O}$ & 1181 & 1182 & $\ldots$ & $\sqrt{ }$ & $\sqrt{ }$ & $\ldots$ & $\ldots$ \\
\hline 3 & 2-Methyl-1-butanol & $\mathrm{C}_{5} \mathrm{H}_{12} \mathrm{O}$ & 1190 & 1191 & $\sqrt{ }$ & $\cdots$ & $\ldots$ & $\sqrt{ }$ & $\sqrt{ }$ \\
\hline 4 & 3-Pentenol & $\mathrm{C}_{5} \mathrm{H}_{10} \mathrm{O}$ & 1218 & 1204 & $\ldots$ & $\sqrt{ }$ & $\ldots$ & $\ldots$ & $\ldots$ \\
\hline 5 & 3-Methyl-3-buten-1-ol & $\mathrm{C}_{5} \mathrm{H}_{10} \mathrm{O}$ & 1344 & - & $\ldots$ & $\ldots$ & $\sqrt{ }$ & $\ldots$ & $\sqrt{ }$ \\
\hline 6 & 3-Octanone* & $\mathrm{C}_{8} \mathrm{H}_{16} \mathrm{O}$ & 1229 & 1230 & $\sqrt{ }$ & $\sqrt{ }$ & $\ldots$ & $\ldots$ & $\sqrt{ }$ \\
\hline 7 & Acetoin* & $\mathrm{C}_{4} \mathrm{H}_{8} \mathrm{O}_{2}$ & 1267 & 1268 & $\cdots$ & $\cdots$ & $\sqrt{ }$ & $\cdots$ & $\ldots$ \\
\hline 8 & 1-Hexanol* & $\mathrm{C}_{6} \mathrm{H}_{14} \mathrm{O}$ & 1333 & 1335 & $\ldots$ & $\ldots$ & $\sqrt{ }$ & $\ldots$ & $\ldots$ \\
\hline 9 & 4-Methyl-5-hexen-2-ol & $\mathrm{C}_{7} \mathrm{H}_{14} \mathrm{O}$ & 1344 & - & $\ldots$ & $\sqrt{ }$ & $\ldots$ & $\ldots$ & \\
\hline 10 & 3-Octanol & $\mathrm{C}_{8} \mathrm{H}_{18} \mathrm{O}$ & 1359 & 1359 & $\sqrt{ }$ & $\sqrt{ }$ & $\ldots$ & $\ldots$ & $\sqrt{ }$ \\
\hline 11 & 4-Methyl-6-hepten-3-ol & $\mathrm{C}_{8} \mathrm{H}_{16} \mathrm{O}$ & 1379 & - & $\cdots$ & $\sqrt{ }$ & $\ldots$ & $\cdots$ & $\cdots$ \\
\hline 12 & 1 -Octen-3-ol* & $\mathrm{C}_{8} \mathrm{H}_{16} \mathrm{O}$ & 1411 & 1411 & $\sqrt{ }$ & $\sqrt{ }$ & $\ldots$ & $\sqrt{ }$ & $\sqrt{ }$ \\
\hline 13 & 3,5,5-Trimethyl-2-hexene & $\mathrm{C}_{9} \mathrm{H}_{18}$ & 1449 & - & $\ldots$ & $\sqrt{ }$ & $\ldots$ & $\ldots$ & $\ldots$ \\
\hline 14 & 2,3-Butanediol* & $\mathrm{C}_{4} \mathrm{H}_{10} \mathrm{O}_{2}$ & 1547 & 1581 & $\ldots$ & $\ldots$ & $\sqrt{ }$ & $\cdots$ & $\cdots$ \\
\hline 15 & 3-Ethyl-4-methyl-3-penten-2-one & $\mathrm{C}_{8} \mathrm{H}_{14} \mathrm{O}$ & 1573 & - & $\cdots$ & $\cdots$ & $\sqrt{ }$ & $\cdots$ & $\ldots$ \\
\hline 16 & Himachala-2,4-diene & $\mathrm{C}_{15} \mathrm{H}_{24}$ & 1583 & - & $\sqrt{ }$ & $\sqrt{ }$ & $\ldots$ & $\sqrt{ }$ & $\ldots$ \\
\hline 17 & $\beta$-Caryophyllene* & $\mathrm{C}_{15} \mathrm{H}_{24}$ & 1602 & 1601 & $\ldots$ & $\ldots$ & $\ldots$ & $\sqrt{ }$ & $\ldots$ \\
\hline 18 & $\alpha$-Amorphene & $\mathrm{C}_{15} \mathrm{H}_{24}$ & 1690 & - & $\ldots$ & $\ldots$ & $\ldots$ & $\sqrt{ }$ & $\ldots$ \\
\hline 19 & Azulene & $\mathrm{C}_{15} \mathrm{H}_{24}$ & 1723 & - & $\sqrt{ }$ & $\ldots$ & $\ldots$ & $\ldots$ & \\
\hline 20 & Methyl salicylate* & $\mathrm{C}_{8} \mathrm{H}_{8} \mathrm{O}_{3}$ & 1767 & 1765 & $\cdots$ & $\cdots$ & $\cdots$ & $\cdots$ & $\sqrt{ }$ \\
\hline 21 & Phenylethyl alcohol & $\mathrm{C}_{8} \mathrm{H}_{10} \mathrm{O}$ & 1871 & 1871 & $\sqrt{ }$ & $\sqrt{ }$ & $\sqrt{ }$ & $\sqrt{ }$ & $\sqrt{ }$ \\
\hline
\end{tabular}


NPA treatment.

MS medium was amended with NPA (Sigma-Aldrich) dissolved in dimethyl sulfoxide (DMSO) to determine whether PAT is critical for mediating the effect of Verticillium VC on plant growth and development. MS medium in the control treatment contained only the same volume of DMSO.

Assessment of GUS activity and staining quantification.

Histochemical staining for GUS activity in transgenic A. thaliana Col-0 seedlings containing DR5::GUS was performed as previously described (Bitas et al. 2015). Staining patterns were observed using a stereomicroscope (Olympus
SZ60) and a compound microscope (Nikon 104) and imaged using the Olympus DP26 camera. Resulting images were imported into Adobe Photoshop (Adobe Systems, San Jose, CA) to quantify stain intensity. Quantification of stain intensity was performed using the ImageJ method.

Assessment of the effect of $\mathrm{CO}_{2}$ produced by fungal culture on plant growth.

$\mathrm{KOH}$ was used to trap $\mathrm{CO}_{2}$ in a tripartite Petri plate (Y-plate). Cocultivation was performed as described above, except that only four A. thaliana seedlings per plate were used due to space limitations. The third compartment was filled with $8 \mathrm{ml}$ of $0.1 \mathrm{M} \mathrm{KOH}$
A

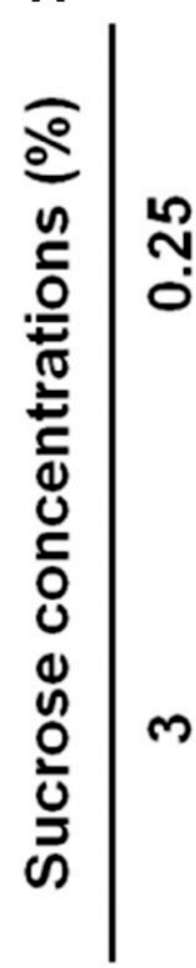

Control
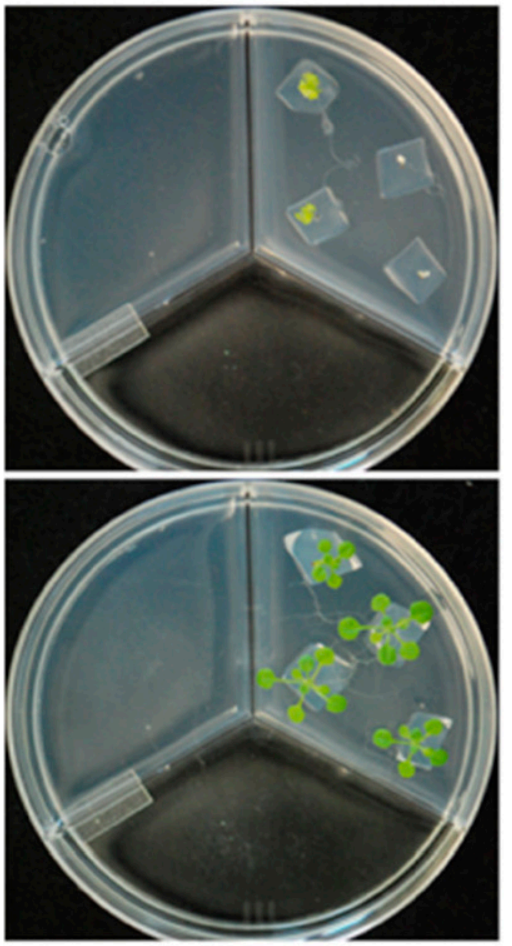

PD322
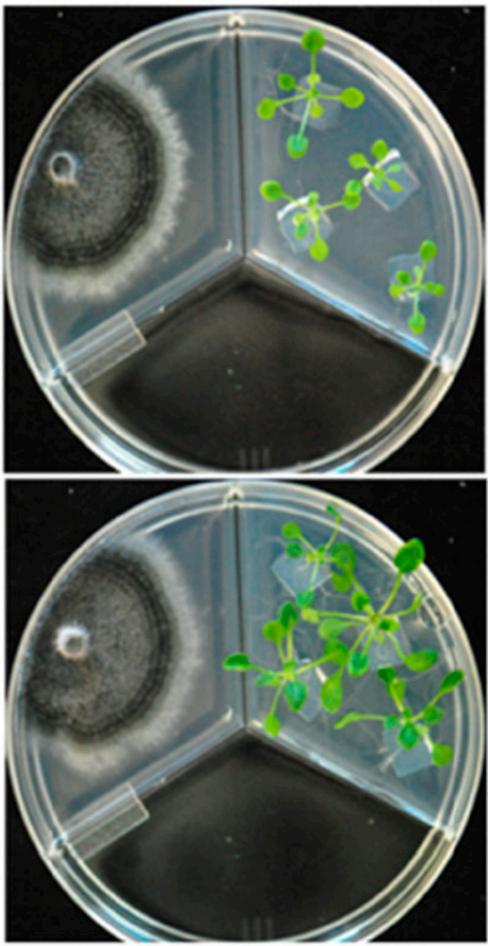

PD413
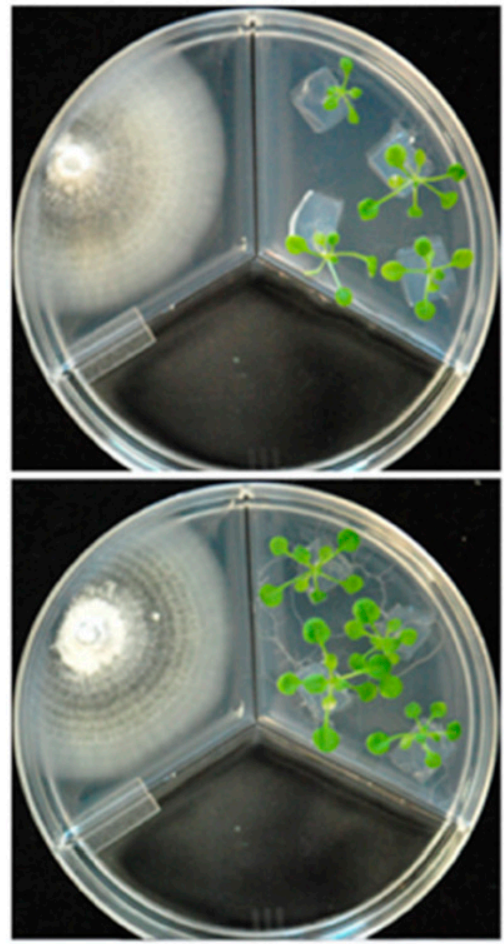

B
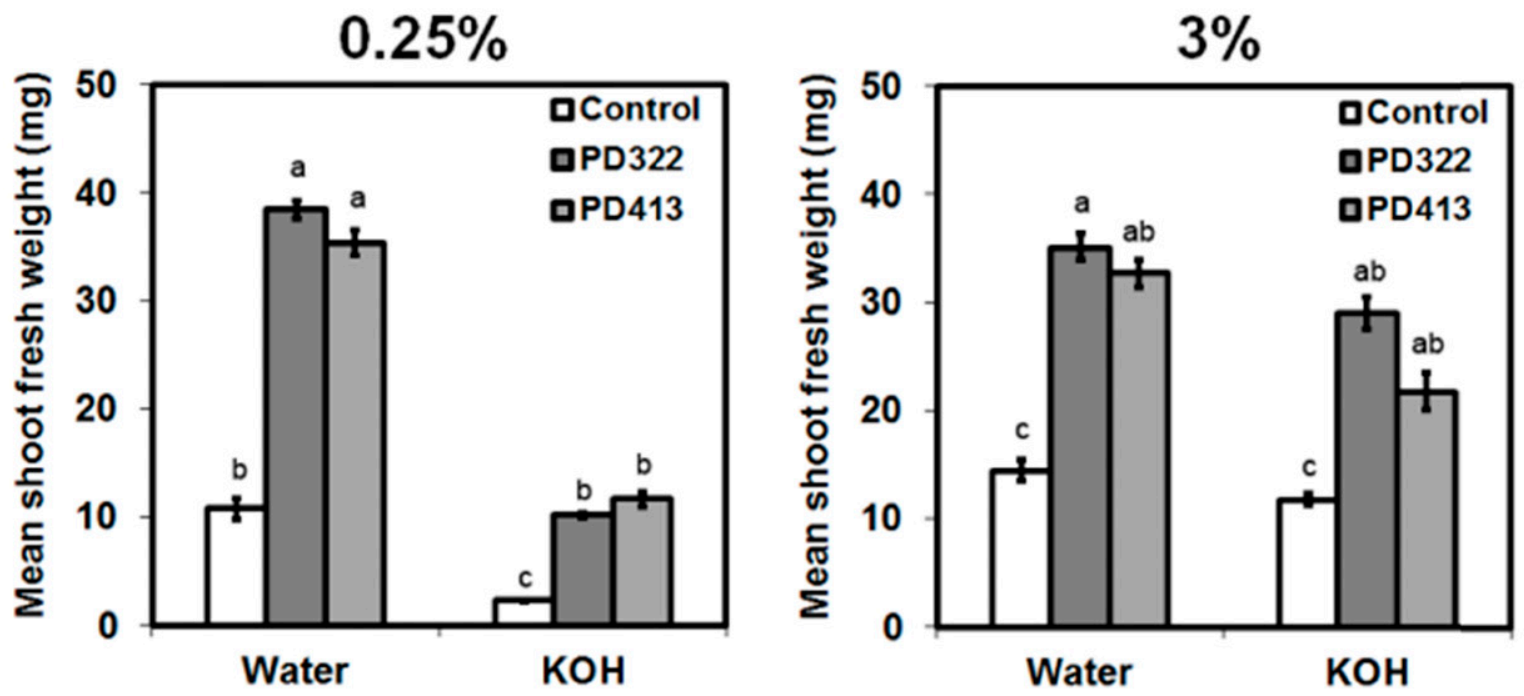

Fig. 8. Growth responses of Arabidopsis thaliana to Verticillium dahliae volatile compounds on media with different amounts of sucrose. Col-0 seedlings grown on medium supplemented with low (0.25\%) and high (3\%) sucrose were cocultivation with no fungus (Control) and V. dahliae strains PD322 and PD413 in the absence and presence of $0.1 \mathrm{M} \mathrm{KOH}$ for 14 days. A, Representative images of treatments in the presence of $0.1 \mathrm{M} \mathrm{KOH}$ and $\mathbf{B}$, shoot fresh weights after individual treatments are shown. Values shown correspond to the mean \pm standard error of data from three replicates $(n=12)$. Different letters indicate significant differences among the treatments within each group according to Tukey's test at $P=0.05$. 
or water. After 14 days of cocultivation, shoot fresh weight was measured.

\section{Analysis of VC produced by Verticillium spp.}

After sealing vials containing PDA slant inoculated with individual strains with breathable film, they were incubated at $22^{\circ} \mathrm{C}$ for 11 days. After replacing the film with a screw cap containing gas-tight silicone/Teflon septa, they were incubated at $22^{\circ} \mathrm{C}$ for 1 day to accumulate $\mathrm{VC}$ in headspace. For VC extraction, the solid phase microextraction fiber was inserted into the vial for $1 \mathrm{~h}$. To determine which fiber coating works best for capturing VC (Stoppacher et al. 2010), the following materials were tested: $100 \mu \mathrm{m}$ polydimethylsiloxane (PDMS), $85 \mu \mathrm{m}$ carboxen (CAR)/PDMS, $65 \mu \mathrm{m}$ PDMS/divinylbenzene (DVB), 50/30 $\mu \mathrm{m}$ DVB/CAR/PDMS, and $7 \mu \mathrm{m}$ PDMS (SigmaAldrich). Because the largest number of compounds was extracted using the DVB/CAR/PDMS 50/30- $\mu$ m fiber coating, this fiber was chosen for capturing VC produced by Verticillium spp. VC released from PDA were also analyzed to help identify which GC peaks corresponded to background signals.

Extracted VC were analyzed using a nontargeted GC-MS method employing the QP 2010 Ultra GC-MS system (Shimadzu, Japan). An Rtx-Wax capillary column ( $60 \mathrm{~m}$ by $0.25 \mathrm{~mm}$ by $0.25 \mu \mathrm{m})$ (RESTEK, USA) was used for GC. The VC bound to the fiber were desorbed for $2 \mathrm{~min}$ using a split/splitless injector (splitless mode). The temperature program was as follows: $35^{\circ} \mathrm{C}$ for $5 \mathrm{~min}$, then ramped to $230^{\circ} \mathrm{C}$ at $5^{\circ} \mathrm{C} / \mathrm{min}$, and kept for $15 \mathrm{~min}$. Helium was used as the carrier gas with a constant flow rate of $1 \mathrm{ml} / \mathrm{min}$. The injection, transfer line, and ion source temperatures were all set at $230^{\circ} \mathrm{C}$. An electron ionization source set at $70 \mathrm{eV}$ was used. Data acquisition started at $1.5 \mathrm{~min}$ and the mass scan range was 35 to $500 \mathrm{~m} / \mathrm{z}$. To calculate retention indices of individual compounds, $1 \mu$ of a mixture of alkane standards $\left(C_{7}\right.$ to $\mathrm{C}_{40}$ containing each alkane in $\mathrm{n}$-hexane at $100 \mathrm{mg} / \mathrm{liter}$ ) was injected. Putative identity of individual VC was determined by comparing their mass spectral profiles and retention index values with those archived in the NIST 11 library.

\section{Statistical analysis.}

The experimental design was completely randomized, consisting of three replications for each treatment. Each experiment was repeated at least twice. Analyses of variance for data were performed using Minitab 17.3 (Minitab Inc., State College, PA). The significance of treatment was determined by the magnitude of the $F$ value $(P=0.05)$. When a significant $F$ test was obtained for treatment, separation of the means was conducted using Tukey's test at $P=0.05$.

\section{ACKNOWLEDGMENTS}

We thank S. May and K. M. Brown for allowing us to use their equipment, and D. Desveaux and M. Axtell for supplying transgenic Col-0 containing DR5::GUS and $N$. benthamiana, respectively.

\section{LITERATURE CITED}

Agrios, G. N. 2005. Plant diseases caused by fungi. Pages 385-614 in: Plant Pathology. Academic Press, San Diego, CA.

Bailly, A., Groenhagen, U., Schulz, S., Geisler, M., Eberl, L., and Weisskopf, L. 2014. The inter-kingdom volatile signal indole promotes root development by interfering with auxin signalling. Plant J. 80: 758-771.

Bailly, A., and Weisskopf, L. 2012. The modulating effect of bacterial volatiles on plant growth. Plant Signal. Behav. 7:79-85

Baldwin, I. T. 2010. Plant volatiles. Curr. Biol. 20:R392-R397.

Bergström, L. G. W. 2008. Chemical communication by behaviour-guiding olfactory signals. Chem. Commun. (Cambridge, UK) 34:3959-3979.

Bitas, V., Kim, H.-S., Bennett, J. W., and Kang, S. 2013. Sniffing on microbes: Diverse roles of microbial volatile organic compounds in plant health. Mol. Plant-Microbe Interact. 26:835-843.
Bitas, V., McCartney, N., Li, N., Demers, J., Kim, J.-E., Kim, H.-S., Brown, K. M., and Kang, S. 2015. Fusarium oxysporum volatiles enhance plant growth via affecting auxin transport and signaling. Front. Microbiol. 6:1248

Blom, D., Fabbri, C., Connor, E. C., Schiestl, F. P., Klauser, D. R., Boller, T., Eberl, L., and Weisskopf, L. 2011. Production of plant growth modulating volatiles is widespread among rhizosphere bacteria and strongly depends on culture conditions. Environ. Microbiol. 13:3047-3058.

Casimiro, I., Marchant, A., Bhalerao, R. P., Beeckman, T., Dhooge, S., Swarup, R., Graham, N., Inzé, D., Sandberg, G., Casero, P. J., and Bennett, M. 2001. Auxin transport promotes Arabidopsis lateral root initiation. Plant Cell 13:843-852.

Chawla, S., Woodward, J. E., and Wheeler, T. A. 2012. Influence of Verticillium dahliae infested peanut residue on wilt development in subsequent cotton. Int. J. Agron. 2012:1-5.

Chitarra, G. S., Abee, T., Rombouts, F. M., Posthumus, M. A., and Dijksterhuis, J. 2004. Germination of penicillium paneum Conidia is regulated by 1-octen-3-ol, a volatile self-inhibitor. Appl. Environ. Microbiol. 70:2823-2829.

Chung, J. H., Song, G. C., and Ryu, C.-M. 2016. Sweet scents from good bacteria: Case studies on bacterial volatile compounds for plant growth and immunity. Plant Mol. Biol. 90:677-687.

Cordovez, V., Mommer, L., Moisan, K., Lucas-Barbosa, D., Pierik, R., Mumm, R., Carrion, V. J., and Raaijmakers, J. M. 2017. Plant phenotypic and transcriptional changes induced by volatiles from the fungal root pathogen Rhizoctonia solani. Front. Plant Sci. 8:1262.

Crookshanks, M., Taylor, G., and Dolan, L. 1998. A model system to study the effects of elevated $\mathrm{CO}_{2}$ on the developmental physiology of roots: The use of Arabidopsis thaliana. J. Exp. Bot. 49:593-597.

de Weert, S., and Bloemberg, G. V. 2007. Rhizosphere competence and the role of root colonization in biocontrol. Pages 317-333 in: PlantAssociated Bacteria. Springer, Dordrecht, The Netherlands.

Ditengou, F. A., Müller, A., Rosenkranz, M., Felten, J., Lasok, H., van Doorn, M. M., Legué, V., Palme, K., Schnitzler, J.-P., and Polle, A. 2015. Volatile signalling by sesquiterpenes from ectomycorrhizal fungi reprogrammes root architecture. Nat. Commun. 6:6279.

Effmert, U., Kalderás, J., Warnke, R., and Piechulla, B. 2012. Volatile mediated interactions between bacteria and fungi in the soil. J. Chem. Ecol. 38:665-703.

Fradin, E. F., and Thomma, B. P. H. J. 2006. Physiology and molecular aspects of Verticillium wilt diseases caused by $V$. dahliae and $V$. alboatrum. Mol. Plant Pathol. 7:71-86.

Garnica-Vergara, A., Barrera-Ortiz, S., Muñoz-Parra, E., Raya-González, J., Méndez-Bravo, A., Macías-Rodríguez, L., Ruiz-Herrera, L. F., and López-Bucio, J. 2016. The volatile 6-pentyl-2H-pyran-2-one from Trichoderma atroviride regulates Arabidopsis thaliana root morphogenesis via auxin signaling and ETHYLENE INSENSITIVE 2 functioning. New Phytol. 209:1496-1512.

Gil, P., Dewey, E., Friml, J., Zhao, Y., Snowden, K. C., Putterill, J., Palme, K., Estelle, M., and Chory, J. 2001. BIG: A calossin-like protein required for polar auxin transport in Arabidopsis. Genes Dev. 15:1985-1997.

Guo, X., Lu, W., Ma, Y., Qin, Q., and Hou, S. 2013. The BIG gene is required for auxin-mediated organ growth in Arabidopsis. Planta 237: 1135-1147.

Gurung, S., Short, D. P. G., Hu, X., Sandoya, G. V., Hayes, R. J., Koike, S. T., and Subbarao, K. V. 2015. Host range of Verticillium isaacii and Verticillium klebahnii from artichoke, spinach, and lettuce. Plant Dis. 99:933-938.

Herrmann, A. 2010. Volatiles-An interdisciplinary approach. Pages 1-10 in: The Chemistry and Biology of Volatiles. A. Herrmann, ed. John Wiley \& Sons, Ltd, Chichester, UK.

Hiscox, J. D., and Israelstam, G. F. 1979. A method for the extraction of chlorophyll from leaf tissue without maceration. Can. J. Bot. 57:1332-1334

Hung, R., Lee, S., and Bennett, J. W. 2013. Arabidopsis thaliana as a model system for testing the effect of Trichoderma volatile organic compounds. Fungal Ecol. 6:19-26.

Hung, R., Lee, S., and Bennett, J. W. 2015. Fungal volatile organic compounds and their role in ecosystems. Appl. Microbiol. Biotechnol. 99:3395-3405.

Hung, R., Lee, S., Rodriguez-Saona, C., and Bennett, J. W. 2014. Common gas phase molecules from fungi affect seed germination and plant health in Arabidopsis thaliana. AMB Express 4:53.

Hunt, R. 2017. Growth analysis, individual plants. Pages 421-429 in: Encyclopedia of Applied Plant Sciences, E. Arnold, ed. Elsevier, London.

Hutchinson, S. A. 1973. Biological activities of volatile fungal metabolites. Annu. Rev. Phytopathol. 11:223-246.

Inderbitzin, P., Bostock, R. M., Davis, R. M., Usami, T., Platt, H. W., and Subbarao, K. V. 2011. Phylogenetics and taxonomy of the fungal vascular wilt pathogen Verticillium, with the descriptions of five new species. PLoS One 6:e28341. 
Inderbitzin, P., and Subbarao, K. V. 2014. Verticillium systematics and evolution: How confusion impedes Verticillium wilt management and how to resolve it. Phytopathology 104:564-574.

Jefferson, R. A., Kavanagh, T. A., and Bevan, M. W. 1987. GUS fusions: Beta-glucuronidase as a sensitive and versatile gene fusion marker in higher plants. EMBO J. 6:3901-3907.

Jin, C. W., Du, S. T., Chen, W. W., Li, G. X., Zhang, Y. S., and Zheng, S. J. 2009. Elevated carbon dioxide improves plant iron nutrition through enhancing the iron-deficiency-induced responses under iron-limited conditions in tomato. Plant Physiol. 150:272-280.

Kai, M., and Piechulla, B. 2009. Plant growth promotion due to rhizobacterial volatiles-An effect of $\mathrm{CO}_{2}$ ? FEBS Lett. 583:3473-3477.

Kaiser, R. 2006. Flowers and fungi use scents to mimic each other. Science 311:806-807.

Kanchiswamy, C. N., Malnoy, M., and Maffei, M. E. 2015a. Bioprospecting bacterial and fungal volatiles for sustainable agriculture. Trends Plant Sci. 20:206-211.

Kanchiswamy, C. N., Malnoy, M., and Maffei, M. E. 2015b. Chemical diversity of microbial volatiles and their potential for plant growth and productivity. Front. Plant Sci. 6:151.

Kasson, M. T., Short, D. P. G., O’Neal, E. S., Subbarao, K. V., and Davis, D. D. 2014. Comparative pathogenicity, biocontrol efficacy, and multilocus sequence typing of Verticillium nonalfalfae from the invasive Ailanthus altissima and other hosts. Phytopathology 104:282-292.

Klosterman, S. J., Atallah, Z. K., Vallad, G. E., and Subbarao, K. V. 2009. Diversity, pathogenicity, and management of Verticillium species. Annu. Rev. Phytopathol. 47:39-62.

Korpi, A., Järnberg, J., and Pasanen, A.-L. 2009. Microbial volatile organic compounds. Crit. Rev. Toxicol. 39:139-193.

Kottb, M., Gigolashvili, T., Großkinsky, D. K., and Piechulla, B. 2015. Trichoderma volatiles effecting Arabidopsis: From inhibition to protection against phytopathogenic fungi. Front. Microbiol. 6:995.

Kramer, R., and Abraham, W. R. 2012. Volatile sesquiterpenes from fungi: What are they good for? Phytochem. Rev. 11:15-37.

Law, J. H., and Regnier, F. E. 1971. Pheromones. Annu. Rev. Biochem. 40: 533-548.

Lee, S., Yap, M., Behringer, G., Hung, R., and Bennett, J. W. 2016. Volatile organic compounds emitted by Trichoderma species mediate plant growth. Fungal Biol. Biotechnol. 3:7.

Li, N., Alfiky, A., Vaughan, M. M., and Kang, S. 2016. Stop and smell the fungi: Fungal volatile metabolites are overlooked signals involved in fungal interaction with plants. Fungal Biol. Rev. 30:134-144.

Ljung, K., Bhalerao, R. P., and Sandberg, G. 2001. Sites and homeostatic control of auxin biosynthesis in Arabidopsis during vegetative growth Plant J. 28:465-474.

Martínez-Medina, A., Van Wees, S. C. M., and Pieterse, C. M. J. 2017. Airborne signals from Trichoderma fungi stimulate iron uptake responses in roots resulting in priming of jasmonic acid-dependent defences in shoots of Arabidopsis thaliana and Solanum lycopersicum. Plant Cell Environ. 40:2691-2705.

Meldau, D. G., Meldau, S., Hoang, L. H., Underberg, S., Wünsche, H., and Baldwin, I. T. 2013. Dimethyl disulfide produced by the naturally associated bacterium Bacillus sp. B55 promotes Nicotiana attenuata growth by enhancing sulfur nutrition. Plant Cell 25:2731-2747.

Minerdi, D., Bossi, S., Maffei, M. E., Gullino, M. L., and Garibaldi, A. 2011. Fusarium oxysporum and its bacterial consortium promote lettuce growth and expansin A5 gene expression through microbial volatile organic compound (MVOC) emission. FEMS Microbiol. Ecol. 76: 342-351.

Morath, S. U., Hung, R., and Bennett, J. W. 2012. Fungal volatile organic compounds: A review with emphasis on their biotechnological potential. Fungal Biol. Rev. 26:73-83.

Muday, G. K., Maloney, G. S., and Lewis, D. R. 2015. Integration of ethylene and auxin signaling and the developmental consequences of their crosstalk. Pages 175-204 in: Ethylene in Plants. C.-K. Wen, ed. Springer, Dordrecht, The Netherlands.

Naznin, H. A., Kimura, M., Miyazawa, M., and Hyakumachi, M. 2013. Analysis of volatile organic compounds emitted by plant growthpromoting fungus Phoma sp. GS8-3 for growth promotion effects on tobacco. Microbes Environ. 28:42-49.

Nemčovič, M., Jakubíková, L., Víden, I., and Farkaš, V. 2008. Induction of conidiation by endogenous volatile compounds in Trichoderma spp. FEMS Microbiol. Lett. 284:231-236.

Paul, D., and Park, K. S. 2013. Identification of volatiles produced by Cladosporium cladosporioides CL-1, a fungal biocontrol agent that promotes plant growth. Sensors (Basel) 13:13969-13977.

Pegg, G. F., and Brady, B. L., eds. 2002. Verticillium Wilts. CABI, Wallingford, UK
Piechulla, B. 2017. Considering microbial $\mathrm{CO}_{2}$ during microbe-plant cocultivation. Plant Physiol. 173:1529.

Reed, R. C., Brady, S. R., and Muday, G. K. 1998. Inhibition of auxin movement from the shoot into the root inhibits lateral root development in Arabidopsis. Plant Physiol. 118:1369-1378.

Ristova, D., and Busch, W. 2014. Natural variation of root traits: From development to nutrient uptake. Plant Physiol. 166:518-527.

Ruegger, M., Dewey, E., Hobbie, L., Brown, D., Bernasconi, P., Turner, J., Muday, G., and Estelle, M. 1997. Reduced naphthylphthalamic acid binding in the tir3 mutant of Arabidopsis is associated with a reduction in polar auxin transport and diverse morphological defects. Plant Cell 9:745-757

Růzicka, K., Ljung, K., Vanneste, S., Podhorská, R., Beeckman, T., Friml, J., and Benková, E. 2007. Ethylene regulates root growth through effects on auxin biosynthesis and transport-dependent auxin distribution. Plant Cell 19:2197-2212.

Rybakova, D., Rack-Wetzlinger, U., Cernava, T., Schaefer, A., Schmuck, M., and Berg, G. 2017. Aerial warfare: A volatile dialogue between the plant pathogen Verticillium longisporum and its antagonist Paenibacillus polymyxa. Front. Plant Sci. 8:1294.

Ryu, C.-M., Farag, M. A., Hu, C.-H., Reddy, M. S., Wei, H.-X., Paré, P. W., and Kloepper, J. W. 2003. Bacterial volatiles promote growth in Arabidopsis. Proc. Natl. Acad. Sci. USA 100:4927-4932.

Sánchez-López, Á. M., Baslam, M., De Diego, N., Muñoz, F. J., Bahaji, A., Almagro, G., Ricarte-Bermejo, A., García-Gómez, P., Li, J., Humplík, J. F., Novák, O., Spíchal, L., Doležal, K., Baroja-Fernández, E., and Pozueta-Romero, J. 2016. Volatile compounds emitted by diverse phytopathogenic microorganisms promote plant growth and flowering through cytokinin action. Plant Cell Environ. 39:2592-2608.

Schenkel, D., Lemfack, M. C., Piechulla, B., and Splivallo, R. 2015. A meta-analysis approach for assessing the diversity and specificity of belowground root and microbial volatiles. Front. Plant Sci. 6:707.

Schmidt, R., Cordovez, V., de Boer, W., Raaijmakers, J., and Garbeva, P. 2015. Volatile affairs in microbial interactions. ISME J. 9:2329-2335.

Shipley, B., and Meziane, D. 2002. The balanced-growth hypothesis and the allometry of leaf and root biomass allocation. Funct. Ecol. 16:326-331.

Short, D. P. G., Gurung, S., Koike, S. T., Klosterman, S. J., and Subbarao, K. V. 2015. Frequency of Verticillium species in commercial spinach fields and transmission of $V$. dahliae from spinach to subsequent lettuce crops. Phytopathology 105:80-90.

Splivallo, R., Fischer, U., Göbel, C., Feussner, I., and Karlovsky, P. 2009. Truffles regulate plant root morphogenesis via the production of auxin and ethylene. Plant Physiol. 150:2018-2029.

Splivallo, R., Novero, M., Bertea, C. M., Bossi, S., and Bonfante, P. 2007. Truffle volatiles inhibit growth and induce an oxidative burst in Arabidopsis thaliana. New Phytol. 175:417-424.

Stoppacher, N., Kluger, B., Zeilinger, S., Krska, R., and Schuhmacher, R. 2010. Identification and profiling of volatile metabolites of the biocontrol fungus Trichoderma atroviride by HS-SPME-GC-MS. J. Microbiol. Methods 81:187-193.

Ulmasov, T., Murfett, J., Hagen, G., and Guilfoyle, T. J. 1997. Aux/IAA proteins repress expression of reporter genes containing natural and highly active synthetic auxin response elements. Plant Cell 9:1963-1971.

Veresoglou, S. D., Menexes, G., and Rillig, M. C. 2012. Do arbuscular mycorrhizal fungi affect the allometric partition of host plant biomass to shoots and roots? A meta-analysis of studies from 1990 to 2010. Mycorrhiza 22:227-235.

Wright, I. J., and Westoby, M. 2000. Cross-species relationships between seedling relative growth rate, nitrogen productivity and root vs leaf function in 28 Australian woody species. Funct. Ecol. 14:97-107.

Xu, X. Z. S., Wes, P. D., Chen, H., Li, H. S., Yu, M., Morgan, S., Liu, Y., and Montell, C. 1998. Retinal targets for calmodulin include proteins implicated in synaptic transmission. J. Biol. Chem. 273:31297-31307.

Yamagiwa, Y., Inagaki, Y., Ichinose, Y., Toyoda, K., Hyakumachi, M., and Shiraishi, T. 2011. Talaromyces wortmannii FS2 emits $\beta$-caryphyllene, which promotes plant growth and induces resistance. J. Gen. Plant Pathol. 77:336-341.

Zhang, H., Kim, M.-S., Krishnamachari, V., Payton, P., Sun, Y., Grimson, M., Farag, M. A., Ryu, C.-M., Allen, R., Melo, I. S., and Paré, P. W. 2007. Rhizobacterial volatile emissions regulate auxin homeostasis and cell expansion in Arabidopsis. Planta 226:839-851.

\section{AUTHOR-RECOMMENDED INTERNET RESOURCE}

Using the ImageJ method: http://www.lukemiller.org/journal/2007/08/quantifying-western-blotswithout.html 